\title{
Atenolol And Nifedipine Combination Is Better Than Monotherapy: A New Era In Novel Drug Delivery For Hypertension
}

\author{
G.Swapna $^{1,3}$, K. Sesha Maheswaramma ${ }^{2}$, and K. Bhaskar Reddy ${ }^{3 *}$ \\ ${ }^{1}$ Research Scholar, JNTUA, Anantapur - 515-002 Andhra Pradesh, India. \\ Email: swapnagv111@gmail.com \\ ${ }^{2}$ Department of Chemistry, Jawaharlal Nehru Technological University Anantapur College of \\ Engineering, Pulivendula- 516-390 Andhra Pradesh, India. \\ Email: kallurimahi@rediff mail.com \\ ${ }^{3}$ Centre For Pharmaceutical Nanotechnology Department of Pharmaceutics Sri Venkateswara \\ College of Pharmacy, RVS Nagar, Tirupati Road, Chittoor - 517 127. Andhra Pradesh, India. \\ Corresponding author: K. Bhaskar Reddy Email: bhaskurra@gmail.com
}

\begin{abstract}
Hypertension is considered a major health problems globally affect millions of patient.Various study confirms that single drug treatment usually is not adequate to achieve blood pressure goal in most hypertensive patients.In this regard,consideration is given to combination therapy, which offers the potential advantages towards minimizing hypertension in a rapid manner and produces lower adverse effects.SLTs (Sublingual tablets) provides immediate action to enhanced absorption and bioavailability rate. Sublingual tablets are absorbed within the mucus membrane and directly reach in blood systemic circulation. The objective of this ongoing research focused on theatenolol (ATN)and nifedipine (NIF) combined drug deliveryin emergency condition of hypertension. Direct compression technique is used to formulate SLTsby taking different types and concentrations of superdisintegrantsCroscarmellose sodium (CCS) and Crospovidone (CP). Sublimating agents like camphor (CM) and thymol (TY)) also added for better result. FTIR and DSC analysis confirms the ccompatibility results between drug and superdisintegrants.Formulated tablets are evaluated for different parameters and found satisfactory. Formulation F6 considered as the best formulation. The disintegration shows $13 \mathrm{sec}$ and dissolution profile shows $97.36 \%$ drug release at $10 \mathrm{~min}$. Formulation F6 shows better pharmacokinetic activity and antihypertensive activity in compare to pure drug and marketed formulation. A combination of ATN and NIF produces rapid disintegration and dissolution property during an emergency and is a lifesaving approach in hypertension treatment.
\end{abstract}

Keywords:Combination therapy; Hypertension; Direct compression; Atenolol; Nifedipine

\section{Introduction}

A few investigations were directed by the specialists in a preliminary premise to affirm that individual medication couldn't be ready to control hypertension in several patients [1]. The sensitivity to an anti-hypertensive drug varies among hypertensivepatients. Because of the synergistic impact of blend treatment minimum quantity of active drugs is useful towards the decrease of hypertension [2]. For example, young people having high plasmarenin activity are sensitive to B-blockers, angiotensin- convertingenzyme inhibitors or angiotensin II type 1 receptor blockers. In "elderly or those with low plasma renin activity are sensitive to calcium channel blockers" $[3,4]$. It is clear that calcium channel blockers can be added to patients with high plasmarenin activity and treated with $\beta$-blockers. Similarly, it is not clearthat the addition of $\beta$-blockers with calcium channel blockers is better than monotherapy. Here a hypothesis has been made that a combination of $\beta$-blockers with calcium channel blockers would be a better choice as an anti- 
hypertensive agent and also control organ damage. ATN and NIF, the representative drugs for $\beta$-blockersand calcium channel blockers respectively, were used as antihypertensivedrugs in this study.

Atenolol is a $\beta$-blockers that helps in blocking the action of natural chemicals in our body like epinephrine which lowers the heartbeat and blood pressure etc. ß-blockers are the drugs, blockingthe adrenergic receptors enhance the cardiac function such as control heart rhythm, diagnosis of angina and lowdown the blood pressure. $\beta$-blockers are also useful for the patient from a second heart attack and control the heart rate by relaxing the blood vessel for easy blood flow.

Nifedipine as calcium antagonist produce a synergistic effect in a combined form with a high potency in angina treatment. During the combination therapy of nifedipine and atenolol, oxygen demand can be reduced in the primary stage of myocardial infarction whereas the vasodilator effect of nifedipine,enhance the supply of oxygen. Monotherapy of ATN and NIF provide prophylactic treatment but in some situation combination form is more preferable.

Several innovations have been made in drug delivery but oral drug delivery still considered the most preferable route for drug administration. Oral drug delivery provides better therapeutic effect due to accurate dosing, cost-effective therapy, self-medication enhance patient compliance. Sublingual tablets (SLTs) are disintegrate in saliva in a fraction of time in the absence of water [5]. Numerous methods have been developed to formulate SLTs such as wet granulation, spray drying, freeze-drying, direct compression, molding, and sublimation method, etc. [6-8]. The advantages of the SLTs are faster dissolution properties with improved bioavailability, high surface area, and efficient production. Superdisintegrants significantly used in the formulation of SLTs [9-11]

The current research focused on the formulation and development of combination therapy between ATN and NIF SLTs considering superdisintegrants at different ratio by sublimation technique. Developed SLTs evaluated by different parameters, in a comparison with pure drug and marketed formulation.

\section{Materials and methods}

Nifedipine powder was a gift sample fromEmcure Pharma, Pune, India. Atenolol procured from Sigma Aldrich, India.Crospovidone was procured from the Nice laboratory, India.Croscarmellose sodium is obtained from Signet, Mumbai. Similarly, camphor, aspartame, microcrystalline cellulose, magnesium stearate, and talcwere of analytical research-grade and used as received from Divya Chemicals, India.

\section{Formulation of ATN and NIF loaded SLTs}

The sublimation method has been selected to formulate combination therapy of SLTs of ATN and NIF with Superdisintegrants (CCS and CP) at different ratios. Combination therapy considered to formulate seven formulations differently in a manner that formulation $\mathrm{F} 1$ as control doesn't have any sublimating agent with an equal ratio of CS and CP. Formulation F2 and F3 containing $10 \%$ camphor with $20 \% \mathrm{CP}$ and $10 \%$ thymol with $20 \%$ CS respectively. Formulation F4 and F5 contain an equal amount of CP and CS with $15 \%$ camphor and thymol as sublimating agents respectively. Similarly, a variation between disintegrating and sublimating agents such as CP (5\% and 15\%), CS (15\% and $5 \%)$, camphor (10\% and 5\%), and thymol (5\% and $10 \%$ ) observe in formulation F6 and F7 respectively. All ingredients have passed through a \#80 mesh screen before mixing. The screened substances were mixed intimately without magnesium stearate.For lubrication magnesium stearate is added to the mixture shown in Table 1.The powder mixture of all formulations are evaluated for pre-formulation studies (Bulk density, tapped density, Carr's index, Hausener's ratio and angle of repose). Evaluated parameter for all formulation represent in Table 2. The powder blend was slugged and compressed to obtain a tablet by using direct compression technique. "For sublimation of camphor and thymol SLTs are kept inside hot air oven at $60^{\circ} \mathrm{C}$ for $8 \mathrm{~h}$ to obtained a poroussurface" [12]. 
Table 1: Formulation of ATN and NIF loaded SLTs (mg)

\begin{tabular}{lccccccc}
\hline Ingredients & \multicolumn{7}{c}{ Batches } \\
\cline { 2 - 8 } & F1 & F2 & F3 & F4 & F5 & F6 & F7 \\
\hline Nifedipine & 10 & 10 & 10 & 10 & 10 & 10 & 10 \\
\hline Atenolol & 25 & 25 & 25 & 25 & 25 & 25 & 25 \\
\hline Crospovidone & 15 & - & 20 & 10 & 10 & 5 & 15 \\
\hline Croscarmellose sodium & 15 & 20 & - & 10 & 10 & 15 & 5 \\
\hline Camphor & - & 10 & - & 15 & - & 10 & 5 \\
\hline Thymol & - & - & 10 & & 15 & 5 & 10 \\
\hline Aspartame & 5 & 5 & 5 & 5 & 5 & 5 & 5 \\
\hline Lactose & 25 & 25 & 25 & 20 & 20 & 20 & 20 \\
\hline Magnesium stearate & 5 & 5 & 5 & 5 & 5 & 5 & 5 \\
\hline Net weight & 100 & 100 & 100 & 100 & 100 & 100 & 100 \\
\hline
\end{tabular}

\section{Drug compatibility study}

Analytical technique such as FTIR and DSC were used to determine the compatibility of active drug with excipients.In this study, drug and excipients interaction can be determined based on functional group displacement of the compounds confirms the compatibility [13]. The analysis of spectrum have been carried out for pure drug, excipients, and its mixtures to find out any deviation in functional groups (shifting of the band or broadening in spectra) [14].In this current research article, ATN and NIF interaction with superdisintegrants carried out by FTIR and DSC studies.

\section{Fourier transform infrared spectral analysis (FTIR)}

The samples (ATN, NIF, superdisintegrants and its mixtures) have been analyzed in the wave range between 4000-400 $\mathrm{cm}^{-1}$ for FTIR (Shimadzu, Japan) studies to confirm the compatibility study $[15,16]$. By adapting a $\mathrm{KBr}$ pressed disk technique, $\mathrm{KBr}$ is added with the sample (pure drug, excipients, and mixtures) in a 10:1 ratio respectively and finally, a semitransparent pallet has been formed and submitted to the FTIR analysis. Potassium bromide $(\mathrm{KBr})$ is the commonest alkali halide taken for pellet preparation because of high transparency which helps the light to be transmitted to the detector [17-19]. FT-IR analysis used to identify unknown materials and for the determination of purity andcompatibility of the compound.

\section{DSC study}

Differential Scanning Colorimetry (DSC)analysis a graph between molecular weight and temperature $\left(10^{\circ} / \mathrm{min}\right.$ from 0 to $700^{\circ}$ under nitrogen flow rate $50 \mathrm{ml} / \mathrm{min}$ ). the resultant spectrum shows exothermic or endothermic reactions for the sample which depends on the analysis techniqueadapted. DSC takes the first preference for rapid analysis of incompatibility of the pharmaceutical mixture Thus, in this current research DSC (SDT.Q600, USA) is a thermoanalytical method used to study interaction between active drug and excipients. The pure drug,superdisintegrants, and its mixtures were scanned individually to confirm compatibility [20,21].

\section{Post evaluation study of ATN and NIF loaded SLTs \\ Weight variability study}

Randomly selected twenty SLTs from individual formulation were collected to determine the uniformity in the weight of tablets. Individually 
weighed all the tablets using weighing balance (Ohaus, USA). Weight variation for all formulations represent in Table 2

\section{Tablet thickness test}

Varnier caliper is used to find out the thickness of the SLTs. Tablets are placed in between the openings of varnier caliper. Randomly selected 3 tablets from each formulation considered to calculate average thickness presented in Table 2[22].This test will provide information about physical dimension of formulated tablets and its uniformity.

\section{Tablet hardness test}

Hardness played an important role in transportation. The unit for the hardness is $\mathrm{kg} / \mathrm{cm}^{2}$. The force required to break or crack the tablet noted down by using Monsanto hardness tester. The average is represented in Table 2 .

\section{Friabilitytest}

Roche friabilator (Veego instrument corporation, Mumbai) is used to conduct tablet friability test. Randomly 20 tablets were selected from each batch and weighed properly $\left(\mathrm{W}_{0}\right)$, after friabilator (25 rpm for $4 \mathrm{~min}$ ) reweighed the tablets (W). Percentage of friability calculated by the equation mentioned below. Standard limit for $\%$ friability is below $1 \%$ [22].

$\%$ friability $=\left(\mathrm{W}_{0}-\mathrm{W}\right) / \mathrm{W}_{\mathbf{0}} \times \mathbf{1 0 0}$

\section{Wetting Time}

A simple step has been followed to calculate wetting time of the formulated tablets. A double folded tissue paper was placed inside the petri plate having $6 \mathrm{ml}$ distilled water. A water-soluble die (amaranth) added gradually to color the water. Tablets were placed on the tissue paper and the end time was noted, when a completely color (red color) change is observed [23].

\section{Drug content}

Ten tablets randomly selected from each groups were powdered by mortar and pestle. The average quantity of powder dissolved in $15 \mathrm{ml}$ methanol in a conical flask. The solution was further sonicated till a homogeneous solution was obtained. Obtained solution filtered (Whatman filter paper) and after suitable dilution absorbance measure with UV
Spectrophotometer (UV-1800 Shimadzu) for ATN and NIF at $224 \mathrm{~nm}$ and $237 \mathrm{~nm}$ respectively [22].

\section{pH of the SLTs}

Formulated SLTsinvestigated for $\mathrm{pH}$ to avoid irritation.If $\mathrm{pH}$ of SLTs deviated more towards highly acidic or alkali could damage the mucus membrane. So the obtained $\mathrm{pH}$ of a SLTs should be similar to saliva. Absorption of drug could be enhanced if SLTs $\mathrm{pH}$ maintained properly [24]. The digital $\mathrm{pH}$ meter used to identify $\mathrm{pH}$ of a SLTs.

\section{In-vitro disintegration test}

The in-vitro disintegration test is conducted to find out the breaking time of a SLTs using disintegration apparatus (Veego, India). Tablets are inserted inside the tubes present in the basket and moved longitudinally [25]. Distilled water as disintegrating medium taken to conduct the test at $37 \pm 0.5^{\circ} \mathrm{C}$ temperature.

\section{In vitro dissolution test for SLTs}

Single basket type dissolution apparatus (Lab India, DS 8000) is used to determine the percentage of drug release from the formulated SLTs[22]. Randomly selected SLTs from each formulation considered for the test. Dissolution results may differ due to different types of superdisintegrats and sublimating agents at various concentrations in each formulation of SLTs. The dissolution apparatus contains a 900 $\mathrm{ml}$ buffer solution $\mathrm{pH} 6.8$ at $37 \pm 0.5^{\circ} \mathrm{Cand}$ the shaft rotates at $100 \mathrm{rpm}$. A sample $(5 \mathrm{~mL})$ of aliquot was withdrawn at different time interval and replaced the same to maintain the concentration. After a suitable dilution collected samples were analyzed under UV Spectrophotometer to analyze ATN and NIF at $224 \mathrm{~nm}$ and $237 \mathrm{~nm}$ respectively [22].

\section{In-vivo studies}

Animal selection

In this study all the animals (Male Wistar albino rats) are housed under the standard conditions and clinically examined. Animal were provided free access to pellet, food, and water.The animals were preserved in a cleanroom maintaining temperature $20-25^{\circ} \mathrm{C}$ with a $12 \mathrm{~h}$ light and dark cycle and controlled RH $60-70 \%$. 
All the animals divided into 4 groups having 6 animals each (age: 4-8weeks; weight: 200$250 \mathrm{~g}$ ). The animal ethical clearance was approved before performing the study.

Group-I contained control animals

Group-II was administered with a pure antihypertensive drug

Group-III formulation F6 (Best formulation)

Group-IV comprised of marketed antihypertensive tablets (Aten $25 \mathrm{mg}$ Tablet (ATN), Calcigard $10 \mathrm{mg}$ Tablet (NIF))

\section{In-vivoPharmacokinetic Studies}

All the animals kept overnight fasting before the experiment and food were provided during the post $2 \mathrm{~h}$ administration of the dosing. The animal restraint device is used to expose the head of the animal during SLT administration. Both the jaws of the mouth were separated by the help of wood made tongue depressor to place the SLT easily. $2 \mathrm{ml}$ of water was supplied to disintegrate the tablet. To avoid chewing animals mouth was kept open for 1 min using gentle strain to allow complete disintegration of SLTs. Blood samples $(0.2 \mathrm{ml}$ each $)$ were collected from the retro-orbital plexus/tail vein of the pre-anaesthetized animals at the regular time intervals $(0.5,1,1.5,2,3,4,6,8,10,12,18$ and $24 \mathrm{~h}$ ) after the administration of the tablet. Blood samples were centrifuged for $10 \mathrm{~min}$ at 3000rpm for the extraction of plasma. HPLC technique is used to analyze drug content $[26,27]$. The obtained data used to determine pharmacokinetic parameters. The obtaineddata were fitted to one compartment open model and analyzed for pharmacokinetic parameters $\left(\mathrm{C}_{\max }\right.$, $\left.\mathrm{t}_{\max }, \mathrm{AUC}_{\mathrm{o}-\mathrm{t}}, \mathrm{Ke}, \mathrm{t}_{1 / 2}\right)$ using PK solver software.

\section{Hypertension induction}

Subcutaneous administration of $20 \mathrm{mg} / \mathrm{kg} /$ week, dose of methylprednisolone acetate once a week for two weeks to induce hypertension. Methylprednisolone acetate retain salt in the animal model became hypertensive. The blood pressure was frequently monitoredfor the animals and the systolic pressure range in 160$190 \mathrm{~mm}$ of $\mathrm{Hg}$ was considered as a hypertensive rat $[28,29]$

\section{Blood pressure measurement:}

All the selected hypertensive animal was segregated into groups. All groups except the control induced hypertension by methylprednisolone acetate. To find out the antihypertensive effect, animal models feed with a subsequent amount of dose.At the prescribed time interval systolic blood pressure was checked.Small animal tail noninvasive blood pressure system based on tail-cuff technique is adopted to check the blood pressure for each animal. The systolic blood pressure recorded by a non-invasive tail-cuff system using the CODA II TM.

\section{Stability study}

Stability studies for the best formulation under a controlled environment by maintaining Indian weather conditions is needed to estimate shelf life. The chemical stability can be performed by several evaluation tests for the best formulation. Stability study performed in a stability chamberas per ICH (international conference of harmonization) guideline for six months at $40^{\circ} \mathrm{C} \pm 2^{\circ} \mathrm{C} / 75 \% \pm 5 \%$ RH. Various stability parameters e.g. physical appearance, drug content, in vitro dissolution and in vitro disintegration studies were evaluated in triplicate.

\section{Results and Discussion \\ Properties of mixture}

Preformulation is a set of research studies that concentrate on the physicochemical residences of a brand new medicine, would affect the drug's overall formulation of dosage form and its performance. To decide the character and analysis of properties of given compound bulk and tapped density are the critical parameters to be conducted. These residences of the given compound may also vary because of the crystallization and homogeneous blending of the compounds. The density of the sample mixture additionally impacts the compression and flow property of the final product. Preformulation studies have done forATN and NIF combination, for all seven formulations with different excipients at various ratios reported in Table 2. Obtained data confirms that the bulk density of the formulations lies between 0.384 to 0.555 $\mathrm{gm} / \mathrm{ml}$, tapped density varies between 0.434 to $0.625 \mathrm{gm} / \mathrm{ml}$, angle of repose range between 
25.98 to 31.03 , Carr's index between 8.18 to14.28 and Hauser's ratio value foundin between 1.08 to 1.16 . Obtained results were as per the limit and observed excellent flow property for each formulations.

Table 2: Pre-formulation study ofATN and NIF loaded powders(Formulation F1- F7)

\begin{tabular}{|c|c|c|c|c|c|c|c|}
\hline $\begin{array}{l}\text { Pre- } \\
\text { Compression } \\
\text { Parameter }\end{array}$ & F1 & F2 & F3 & F4 & F5 & F6 & F7 \\
\hline Bulk density & $0.454 \pm 0.13$ & $0.416 \pm 0.51$ & $0.555 \pm 0.41$ & $0.476 \pm 0.61$ & $0.384 \pm 0.11$ & $0.416 \pm 0.81$ & $0.454 \pm 0.77$ \\
\hline $\begin{array}{l}\text { Tapped } \\
\text { density }\end{array}$ & $0.515 \pm 0.41$ & $0.480 \pm 1.73$ & $0.625 \pm 0.12$ & $0.555 \pm 0.51$ & $0.434 \pm 0.92$ & $0.458 \pm 0.63$ & $0.495 \pm 0.81$ \\
\hline $\begin{array}{l}\text { Angle of } \\
\text { repose }\end{array}$ & $25.98 \pm 1.07$ & $28.15 \pm 0.75$ & $30.88 \pm 1.09$ & $31.03 \pm 0.83$ & $29.16 \pm 0.03$ & $26.93 \pm 0.84$ & $29.01 \pm 0.04$ \\
\hline Carr's index & $11.81 \pm 0.52$ & $13.33 \pm 0.61$ & $11.11 \pm 53$ & $14.28 \pm 0.91$ & $11.53 \pm 1.05$ & $9.16 \pm 0.72$ & $8.18 \pm 0.63$ \\
\hline $\begin{array}{l}\text { Hausner's } \\
\text { ratio }\end{array}$ & $1.13 \pm 0.71$ & $1.15 \pm 0.91$ & $1.12 \pm 0.81$ & $1.16 \pm 0.75$ & $1.13 \pm 0.92$ & $1.10 \pm 0.51$ & $1.08 \pm 0.48$ \\
\hline
\end{tabular}

\section{Compatibility studies}

All the drugs showsphysical, chemical, and therapeutical properties that need special consideration before the final formulation. These points need to be focused to decide the ratio of the drug to combine with the appropriate excipients within a specific limit before the final dosage shape. The objective behind the preformulation study is to take a look at the elegant, stable, powerful, and secure dosage formulation with the aid of using setting up kinetic study profile, compatibility with the excipients, and set up the Physico-chemical parameter ofnew drug development.

\section{FTIR study}

To perform this study, theactive drugs, superdisintegrants, and its mixtures were selected to determine the compatibility.FTIR spectra of active drugs (ATN and NIF), superdisintegrants(CCS and $\mathrm{CP}$ ), and their mixtures represent in figure 1. Spectra for atenolol, CCS, and CP have shown different spectra with different peak positions. CCS and
CP show broad peaks whereas atenolol and mixture of atenolol with CCS and CP have shown crystalline peaks. The obtained result reveals that individual superdisintegrants and active drug shows different spectra which are different from each other. FTIR spectra shows that major peaks of pure atenolol at 3348.72 , 3161.06, 2967.52, 1631.12, 1516.32, 1238.15 $\mathrm{cm}^{-1}$ are matching (Highlighted in FTIR spectrum by a straight line) with the mixture of atenolol,CCS and CP. Figure 2 represents the spectra of nifedipine, CP, CCS, and their combinations. Pure nifedipine, $\mathrm{CP}$, and CCS have shown different spectrums. Here also the major peaks appear at 3324.44, 2955.75, $1220.49 \mathrm{~cm}^{-1}$ for nifedipine shows a clear match (indicated in FTIR spectrum by a straight line) with nifedipine with $\mathrm{CP}$ and CCS.

FTIR result with negligible change in IR spectrum confirms that no chemical interaction found betweenactive drugs (ATN and NIF) with superdisintegrants (CCS and CP). So it concludes that the active drug is compatible and maintained its property. 


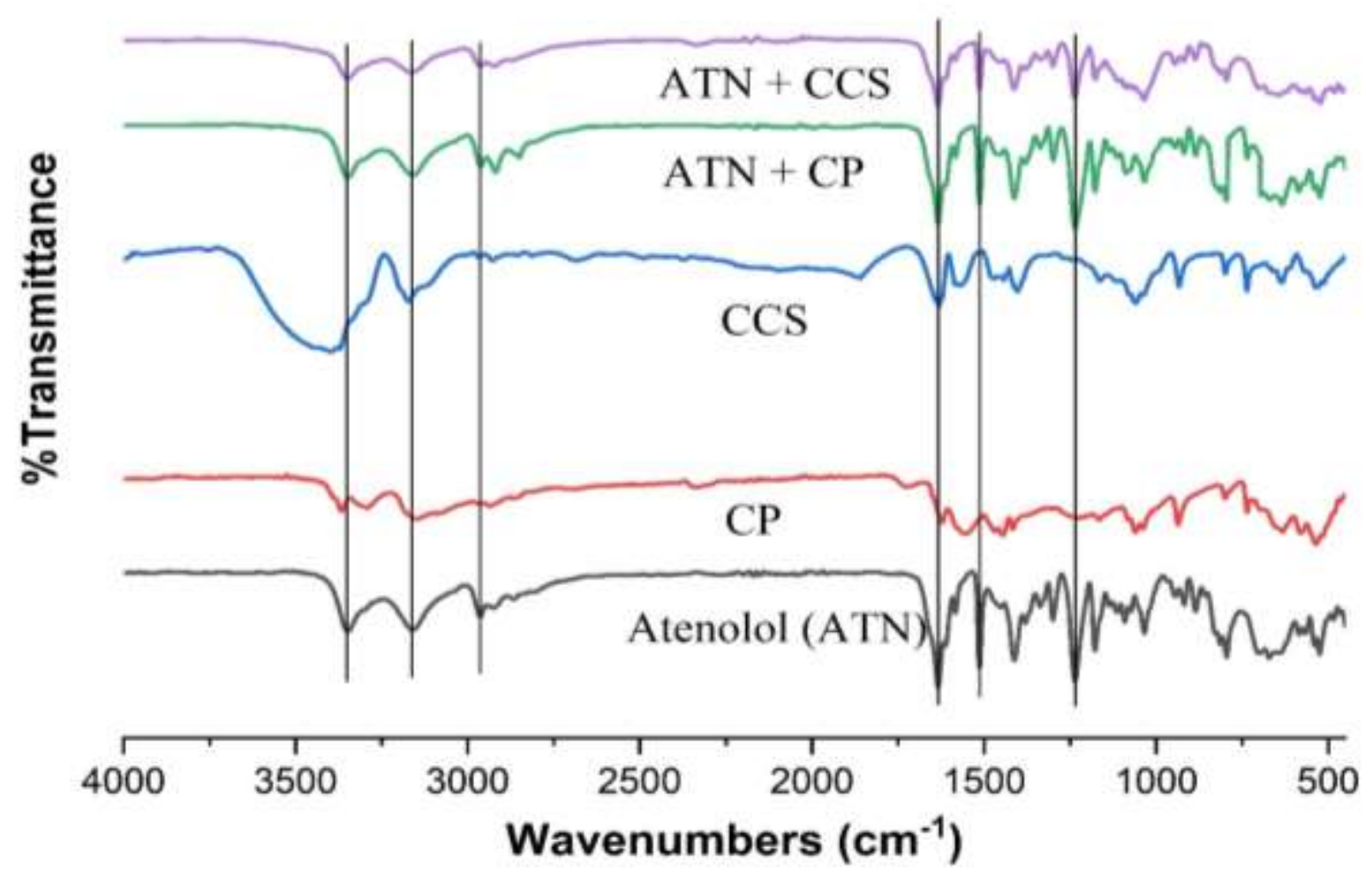

Figure 1: FTIR spectrum for ATN, CP, CCS and its mixtures

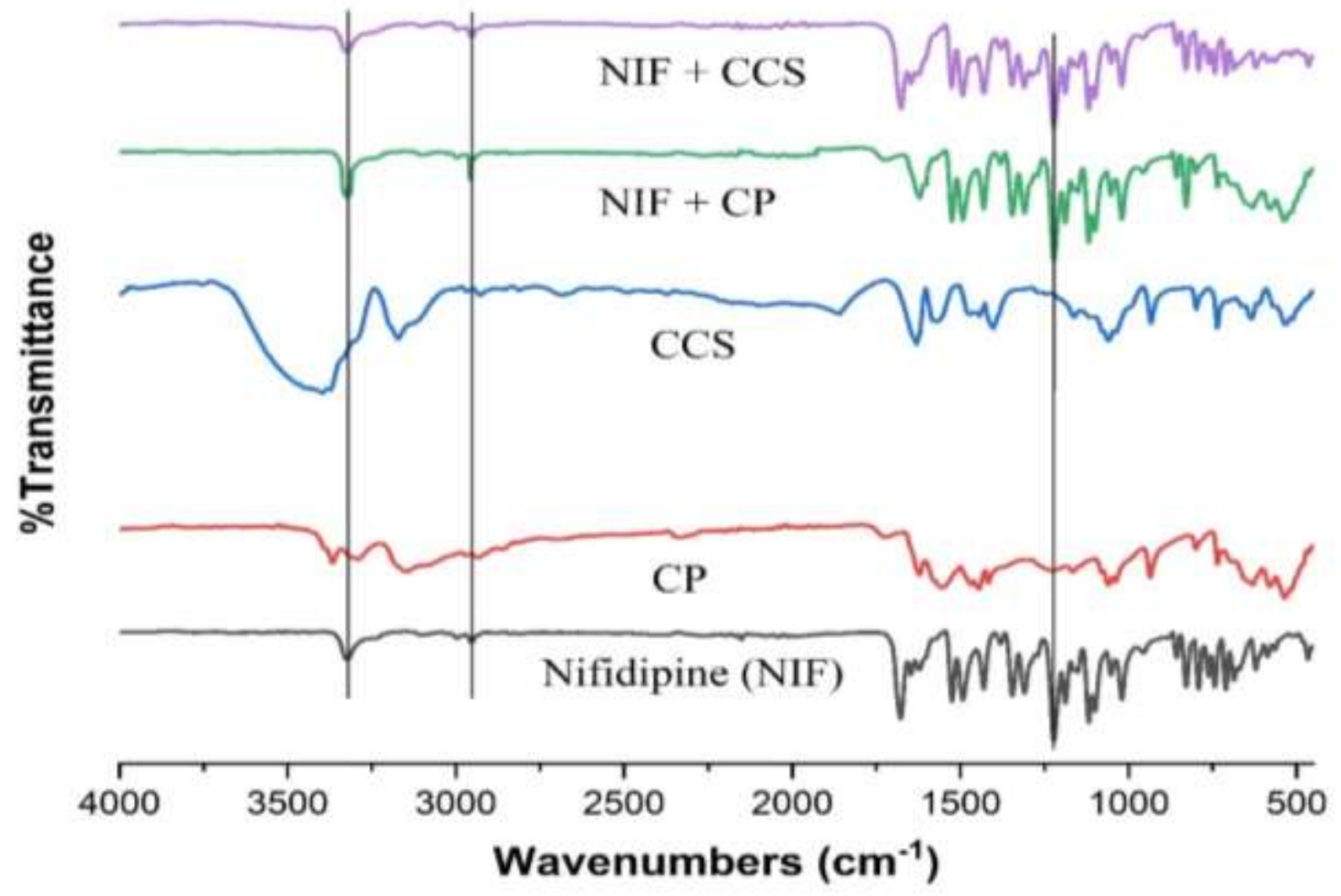

Figure 2: FTIR spectrum of NIF, CP, CCS and its mixtures 


\section{DSC study}

DSC techniqueis performed to know the compatibility of active drugs (ATN and NIF) with superdisintegrants (CCS and $\mathrm{CP}$ ) and its mixtures.In DSC observe samples are heated thermally for drug, superdisintegrants, and its mixtures to verify the chemical compatibility. Submitted samples have shown endothermic peaks. Result have shown different endothermic peaksfor atenolol, CP and CCS at 147.79, 130.91 , and $154.16^{\circ} \mathrm{C}$ respectively in figure 3 .
Whereas atenolol, $\mathrm{CP}$, and CCS mixtures have shown endothermic peaks at 147.79, 149.55, and $150.43^{\circ} \mathrm{C}$ respectively. Figure 4 reveals that nifedipine, CP, and CCS mixture have shown endothermic peaks at 170.52, 171.57, and $174.12^{\circ} \mathrm{C}$ respectively. Aminor change ofthe DSC spectrum confirms that the pure drugs (atenolol and nifedipine) have shown good compatibility with superdisintegrants(CP and CCS).

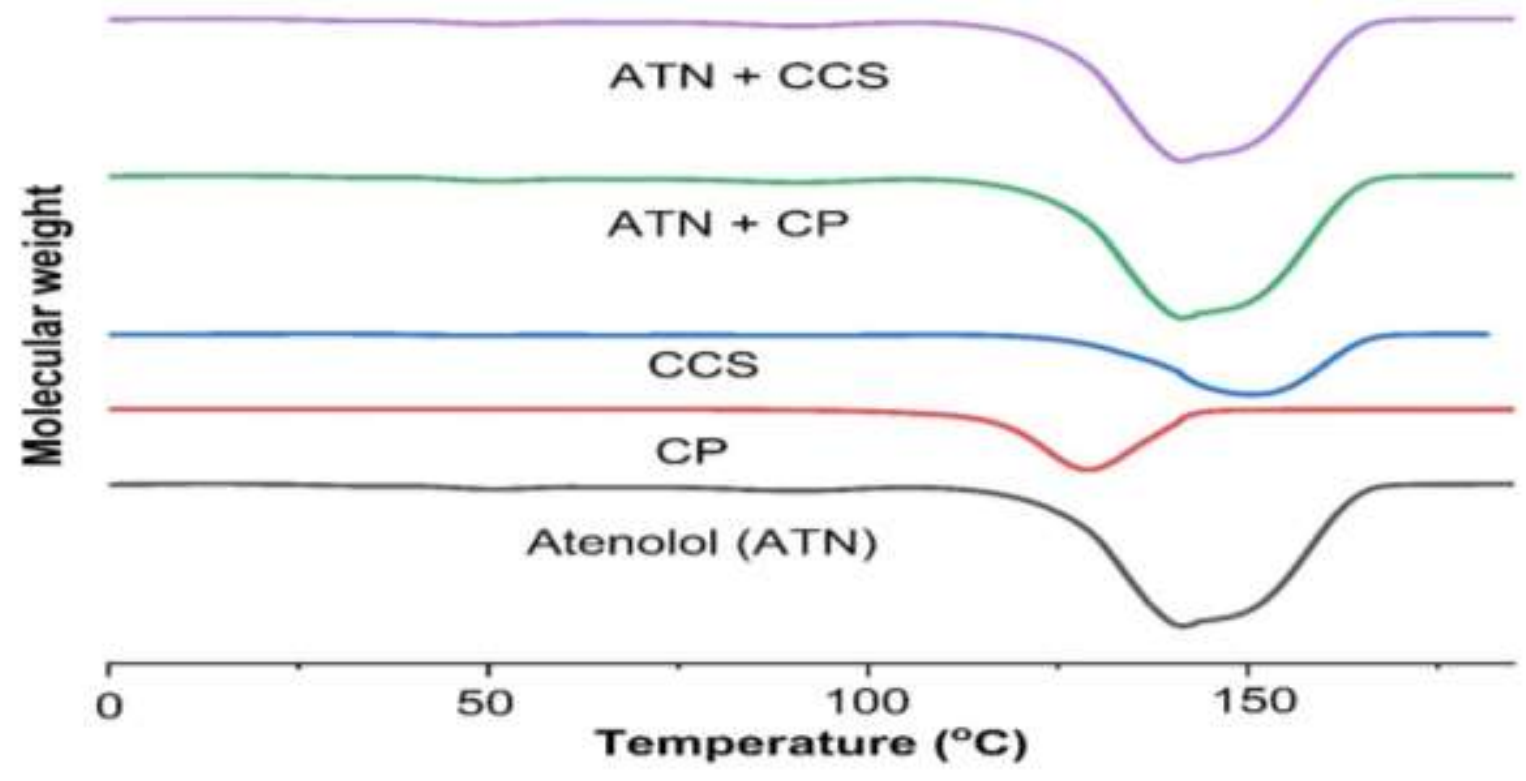

Figure 3:DSC Spectra of pure ATN, CP, CCS and its mixtures

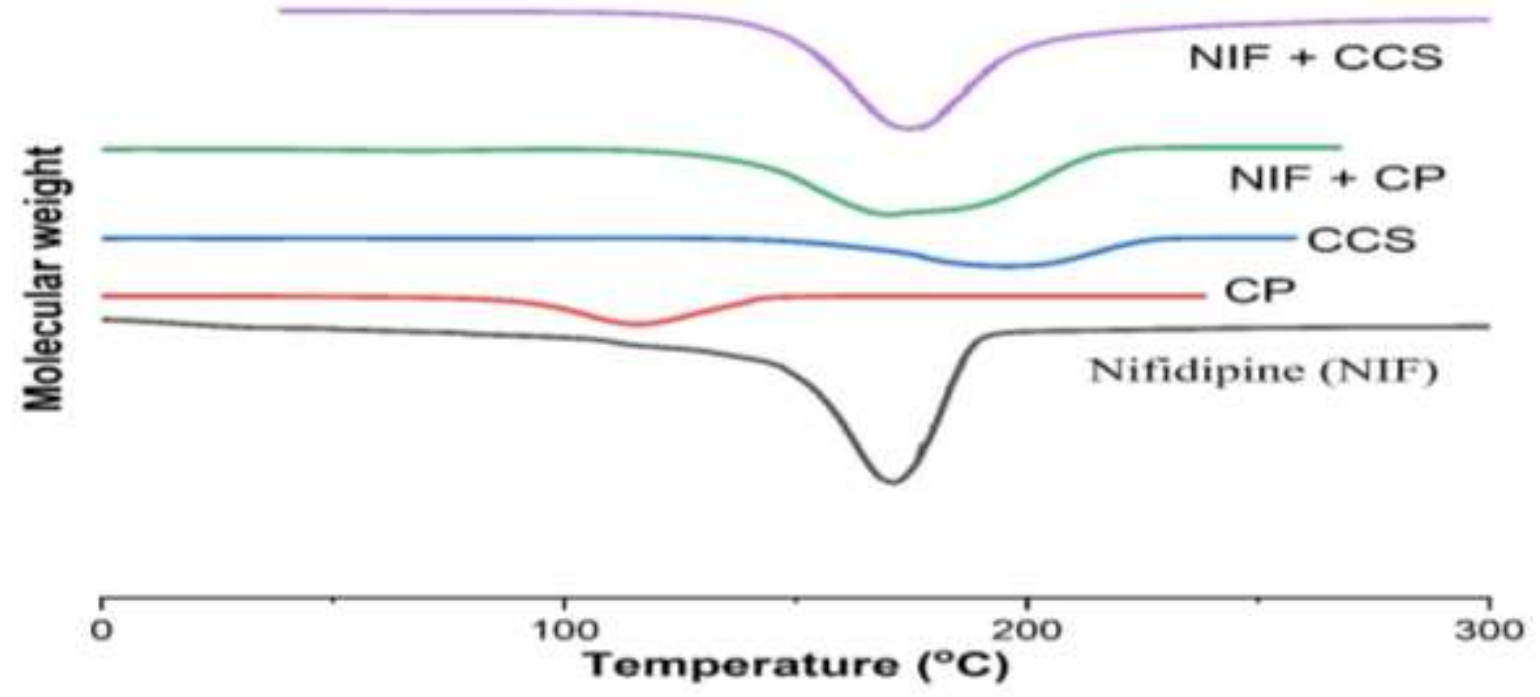

Figure 4:DSC spectrum of NIF, CP, CCS and its mixtures 


\section{Physical Evaluation of ATN and NIF loaded SLTs}

An evaluation study has been performed for ATN and NIF combined SLTs formulation F1F7. Table 3 listed all the post-evaluation parameters for all formulations such as average weight of SLTs found to be 99 to $102 \mathrm{mg}$. Thickness of the SLTs in the range of 2.61 to3.05mm. Hardness for SLTs is 2.32 to 3.03 $\mathrm{kg} / \mathrm{cm}^{2}$. Friability ranges from 0.39 to $0.73 \%$ which is below $1 \%$. Similarly, drug content $\%$ ranges between 97.8 to $99.75 \%$, surface $\mathrm{pH}$ found to be 5.98 to 6.71 , andwetting time lies between 20.6 to 30 seconds. In vitro disintegration results shows in the rangebetween 13 to 25 seconds.

Table 3: Post-compression parameters for ATN and NIF loaded SLTs (formulation F1-F7)

\begin{tabular}{lllllllll}
\hline $\begin{array}{l}\text { Batch } \\
\text { no }\end{array}$ & $\begin{array}{l}\text { Tablet } \\
\text { Weight } \\
\text { variation } \\
(\mathbf{m g})\end{array}$ & $\begin{array}{l}\text { Tablet } \\
\text { Thickness } \\
(\mathbf{m m})\end{array}$ & $\begin{array}{l}\text { Tablet } \\
\text { Hardness } \\
\left(\mathbf{k g} / \mathbf{c m}^{2}\right)\end{array}$ & $\begin{array}{l}\text { Tablet } \\
\text { Friability } \\
(\boldsymbol{\%})\end{array}$ & $\begin{array}{l}\text { Drug } \\
\text { content } \\
(\%)\end{array}$ & $\begin{array}{l}\text { Wetting } \\
\text { time (sec) }\end{array}$ & $\begin{array}{l}\text { Disintegration } \\
\text { time (sec) }\end{array}$ & $\begin{array}{l}\text { Surface } \\
\mathbf{p H}\end{array}$ \\
\hline F1 & $102 \pm 0.06$ & $2.61 \pm 0.02$ & $2.4 \pm 0.01$ & $0.41 \pm 0.03$ & $99.03 \pm 0.06$ & $26.02 \pm 0.04$ & $20 \pm 0.03$ & 6.5 \\
\hline F2 & $101 \pm 0.41$ & $3.02 \pm 0.06$ & $2.32 \pm 0.3$ & $0.67 \pm 0.04$ & $99.75 \pm 0.1$ & $22.1 \pm 0.51$ & $15 \pm 0.31$ & 5.76 \\
\hline F3 & $100 \pm 0.12$ & $2.63 \pm 0.08$ & $2.61 \pm 0.06$ & $0.39 \pm 0.3$ & $97.81 \pm 0.21$ & $23.73 \pm 0.8$ & $18.4 \pm 0.71$ & 6.37 \\
\hline F4 & $99 \pm 2.32$ & $2.75 \pm 0.18$ & $3.01 \pm 0.05$ & $0.63 \pm 0.02$ & $98.15 \pm 1.02$ & $22.63 \pm 0.05$ & $16 \pm 0.01$ & 5.98 \\
\hline F5 & $100 \pm 0.03$ & $3.05 \pm 0.1$ & $2.33 \pm 0.16$ & $0.58 \pm 0.2$ & $97.8 \pm 1.36$ & $23.06 \pm 0.01$ & $17 \pm 0.2$ & 6.01 \\
\hline F6 & $100 \pm 1.04$ & $2.63 \pm 0.51$ & $2.42 \pm 0.04$ & $0.73 \pm 0.01$ & $99.01 \pm 0.06$ & $19.01 \pm 0.3$ & $13 \pm 0.7$ & 6.03 \\
\hline F7 & $100 \pm 0.9$ & $2.73 \pm 0.14$ & $3.03 \pm 0.1$ & $0.65 \pm 0.1$ & $98.74 \pm 1.01$ & $20.74 \pm 0.04$ & $13.8 \pm 0.03$ & 6.71 \\
\hline
\end{tabular}

Results represent in mean $\pm \mathrm{SD}(\mathrm{n}=3)$

\section{In-vitro dissolution test}

Dissolution study need to perform to know the percentage of drug release of and oral solid dosage form. This test will provide information regarding any changes observed inactive drug or its final product. In vitro dissolution results used in $\mathrm{R} \& \mathrm{D}$ for further development of different formulations.

In our current research work, a combination of ATN (calcium channel blockers) and NIF ( $\beta$-blocker) selected for antihypertensive activity. SLTs are formulated by varying different superdisintegrants $(\mathrm{CP}$ and CCS) at different concentrations. Sublimating agents have better diffusion property helps to improved SLTs bioavailability. Combination therapy shows better results than monotherapy. The combination therapy of drugs have been studied earlier by different researchers and observed better synergistic active. Formulation F1 to F7 developed by using combination of ATN and NIF with varying concentration of superdisintegrants and sublimating agents. Obtained results show variation in release raterepresents in figure 5. Formulation F1 contains a combination of ATN and NIF with superdisintegrants $\mathrm{CP}$ and CSSat equal ratio (15\%) without any sublimating agents shown in Table-1. Percentage of drug release observed in formulation $\mathrm{F} 1$ is $97.39 \%$ at $22 \mathrm{~min}$ for NIF and $99.63 \%$ at $32 \mathrm{~min}$ for ATN. Formulation F2 contains active drugs in a combination with $20 \%$ of CCS as and $10 \%$ camphor. Formulation F2 contain one superdisintegrants and one sublimating agent. Formulation F2 shows $98 \%$ drug release at $16 \mathrm{~min}$ for NIF and $98.96 \%$ at 22 min for ATN. similarly, Formulation F3 is a combination of active drugs, $20 \% \mathrm{CP}$ and $10 \%$ thymol. Formulation F3, NIF shown $97.82 \%$ of drugs released in $20 \mathrm{~min}$ but ATN has shown $98.95 \%$ at 28 . Formulation F2, has shown better drug release than formulation F2 due to the composition of CCS with camphor. CCS has shown two-dimension swelling whereas $\mathrm{CP}$ has little swelling property having capillary action 
on drug release. This could decrease the drug release in formulation F3. Similarly, camphor is a better sublimating agent than thymol. Therefor CCS with camphor in a combined form enhance in vitro disintegration result of SLTs. In formulation, F4 and F5 contain an equal amount of $(10 \%) \mathrm{CCS}$ and $\mathrm{CP}$ but varying with different sublimating agents. Formulation F4 contains $15 \%$ camphor whereas Formulation F5 contains $15 \%$ thymol. Formulation F4 has shown drug release $98.21 \%$ at 12 min for NIF whereas ATN has shown $98.19 \%$ at 18 min. Formulation F5 shows $99.71 \%$ at 16 min for NIF and $97.99 \%$ at 20 min for ATN . Formulation F4 diffuse the drug in a quick manner due to the pores formed by camphor on the tablet surface. Formulation F6 contain CCS and $\mathrm{CP}$ at different concentrations like $15 \%$ and $5 \%$ respectively. In formulation, F6 camphor and thymol used 10\% and 5\%. In formulation, F6 CCS and camphor concentration are more with respect to $\mathrm{CP}$ and thymol to obtain better SLTs. Finally

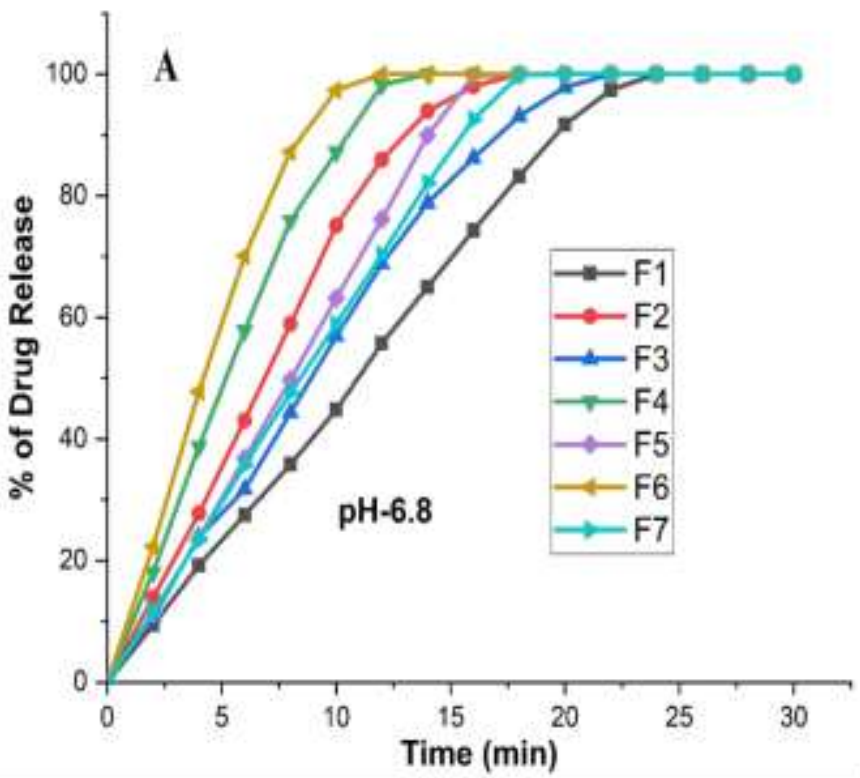

obtaineddrug release percentage for NIF is $97.36 \%$ at $10 \mathrm{~min}$ and for ATN $99.86 \%$ at 16 min in Formulation F6. In formulation F7 we considered the reverse ratio of both sublimating agents and superdisintegrants. Drug release for formulation $\mathrm{F} 7$ is $99.81 \%$ at $18 \mathrm{~min}$ for NIF and for ATN is $99.7 \%$ at $24 \mathrm{~min}$. Obtained dissolution result confirms that formulation F6 is the best formulation. So without any superdisintegrants, sublimating agents alone are unable to fast diffuse rate for active drugs. The combined form of both superdisintegrants, sublimating agents helps for fast disintegration. CCS and Camphor composition at higher concentration with $\mathrm{CP}$ and thymol consider as better formulation. Superdisintegrantsand sublimating agents combinedly used to formulate better SLTs with improved physiological property helps to disintegrate the tablets quickly. It could provide lifesaving treatment in a hypertensive patient.

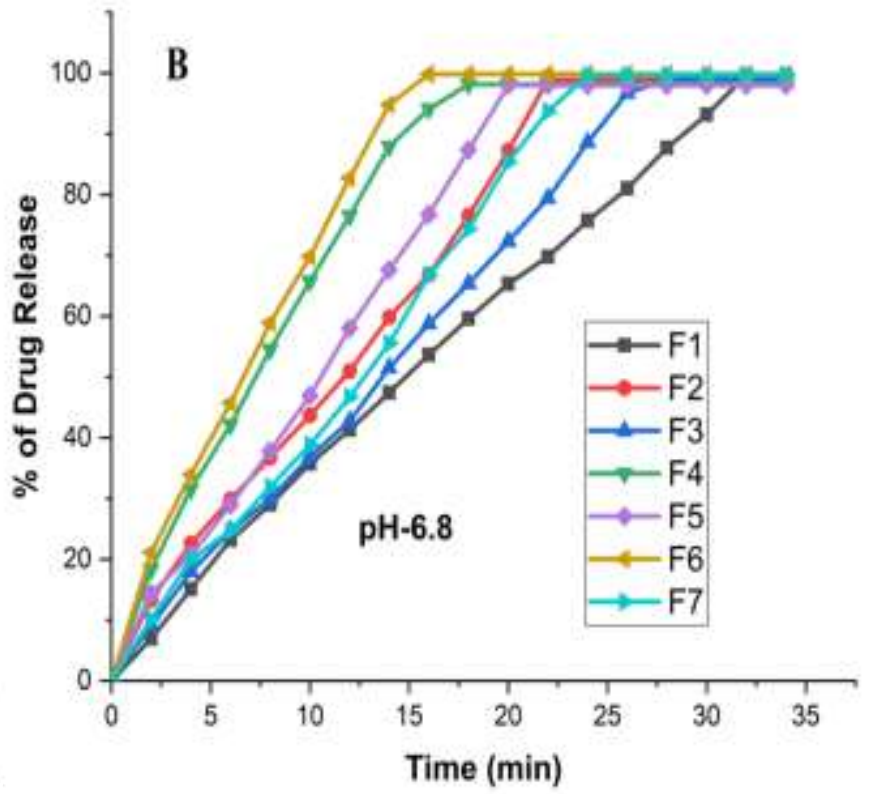

Figure 5:In vitro dissolution study of Formulation F1 to F7 (A) NIF loaded SLTs (B) ATN loaded SLTs

\section{Study of in vivo pharmacokinetic parameters}

For this study healthy Wistar albino rates (male) have been considered and segregate into four groups. Group-I is a control group without induced any hypertensive agent to the rats.
Remaining all other groups groups-II, III, and $\mathrm{IV}$, rats are induced hypertensive agents such as methylprednisolone acetate $20 \mathrm{mg} / \mathrm{kg} /$ week once a week for 2 weeks. Blood pressure measured frequently and the systolic range reaches 180 $\mathrm{mm}$ of $\mathrm{Hg}$ considered as hypertensive rat. For 
group-II pure hypertensive drug (ATN and NIF) was administered. Likewise, Group-III and IV treated with best formulation F6, and marketed antihypertensive drug respectively. Blood samples $(0.5 \mathrm{ml})$ were collected from each group at a regular time intervaland after plasma extraction analyzed under HPLC technique. Various pharmacokinetic parameters $\left(\mathrm{K}_{\mathrm{E}}\left(\mathrm{hr}^{-}{ }^{1}\right)\right.$, $\mathrm{Cl}$ (lit/hr), $\mathrm{V}_{\mathrm{d}}$ (lit), $\mathrm{C}_{\max }(\mu \mathrm{g} / \mathrm{ml}), \max (\mathrm{hr})$ and $\left.\operatorname{AUC}_{\text {(Total) }}(\mu \mathrm{g} / \mathrm{ml} * \mathrm{hr})\right)$ were calculated based on plasma data using PK solver software. Obtained results are reported in Table(4and 5) and figure (6 and 7) for ATN and NIF respectively. Pharmacokinetic parameters for ATN in group III and IV have shown better results than group II. Best formulation F6 have better AUC (Total), $\mathrm{C}_{\max }$, and $\mathrm{Cl}$ compare to marketed formulation and pure drug. Similarly, $t_{\max }$ found in formulation F6 is quite less $2.14 \mathrm{~h}$ than marketed formulation 2.97. It indicates that in formulation F6, drug release is faster. But in marketed formulation $\mathrm{K}_{\mathrm{E}}, \mathrm{V}_{\mathrm{d}}$, have shown better results than the best formulation F6 and pure drug presented in Table 5. Best formulation F6 has shown better in vivo pharmacokinetic result than marketed formulation and pure drug. In Marketed formulation, $\mathrm{V}_{\mathrm{d}}$ for NIF is higher than formulation F6 and pure drug. Best formulation F6 has shown better $t_{\max } 1.42 \mathrm{~h}$ but both marketed and pure NIF shows similar results $2.33 \mathrm{~h}$ and $2.38 \mathrm{~h}$ respectively.In-vivo pharmacokinetic study reveals that formulation F6 has shown better results and could be useful as anti-hypertensive agent.

Table 4.In vivo pharmacokinetic study for ATN

\begin{tabular}{|l|l|l|l|}
\hline Parameters & \multicolumn{1}{|c|}{ Pure drug } & $\begin{array}{l}\text { Test Formulation } \\
\text { (Formulation F6) }\end{array}$ & \multicolumn{1}{|c|}{$\begin{array}{c}\text { Marketed } \\
\text { formulation }\end{array}$} \\
\hline $\mathrm{K}_{\mathrm{E}}\left(\mathrm{hr}^{-1}\right)$ & $0.207 \pm 0.01$ & $0.094 \pm 0.52$ & $0.098 \pm 0.05$ \\
\hline $\mathrm{Cl}(\mathrm{lit} / \mathrm{hr})$ & $0.683 \pm 0.47$ & $1.065 \pm 0.16$ & $0.993 \pm 0.31$ \\
\hline $\mathrm{V}_{\mathrm{d}}(\mathrm{lit})$ & $5.12 \pm 0.61$ & $6.907 \pm 0.03$ & $7.47 \pm 1.02$ \\
\hline $\mathrm{C}_{\max }(\mu \mathrm{gg} / \mathrm{ml})$ & $146.03 \pm 5.02$ & $452.88 \pm 4.02$ & $290.64 \pm 3.37$ \\
\hline $\mathrm{t}_{\max }(\mathrm{hr})$ & $3.48 \pm 0.74$ & $2.14 \pm 0.21$ & $2.97 \pm 0.48$ \\
\hline $\mathrm{AUC}_{(\mathrm{Total})}\left(\mu \mathrm{g} / \mathrm{ml}{ }^{*} \mathrm{hr}\right)$ & $775.6 \pm 14.27$ & $1092.49 \pm 22.75$ & $967.59 \pm 13.04$ \\
\hline
\end{tabular}

Table 5.In vivo pharmacokinetic study of NIF

\begin{tabular}{|l|l|l|l|}
\hline Parameters & \multicolumn{1}{|c|}{ Pure drug } & $\begin{array}{l}\text { Test Formulation } \\
\text { (Formulation F6) }\end{array}$ & \multicolumn{1}{|c|}{$\begin{array}{c}\text { Marketed } \\
\text { formulation }\end{array}$} \\
\hline $\mathrm{K}_{\mathrm{E}}\left(\mathrm{hr}^{-1}\right)$ & $0.119 \pm 0.21$ & $0.215 \pm 0.13$ & $0.113 \pm 0.14$ \\
\hline $\mathrm{Cl}(\mathrm{lit} / \mathrm{hr})$ & $0.736 \pm 0.26$ & $0.847 \pm 0.32$ & $0.665 \pm 0.26$ \\
\hline $\mathrm{V}_{\mathrm{d}}(\mathrm{lit})$ & $6.14 \pm 0.32$ & $3.92 \pm 0.63$ & $5.86 \pm 0.18$ \\
\hline $\mathrm{C}_{\max }(\mu \mathrm{g} / \mathrm{ml})$ & $109.36 \pm 2.14$ & $211.02 \pm 3.83$ & $146.64 \pm 3.37$ \\
\hline $\mathrm{t}_{\max }(\mathrm{hr})$ & $2.38 \pm 0.35$ & $1.42 \pm 0.11$ & $2.33 \pm 0.21$ \\
\hline $\mathrm{AUC}_{(\text {Total })}(\mu \mathrm{g} / \mathrm{ml} * \mathrm{hr})$ & $869.46 \pm 11.93$ & $1088.46 \pm 18.15$ & $1196.91 \pm 23.81$ \\
\hline
\end{tabular}




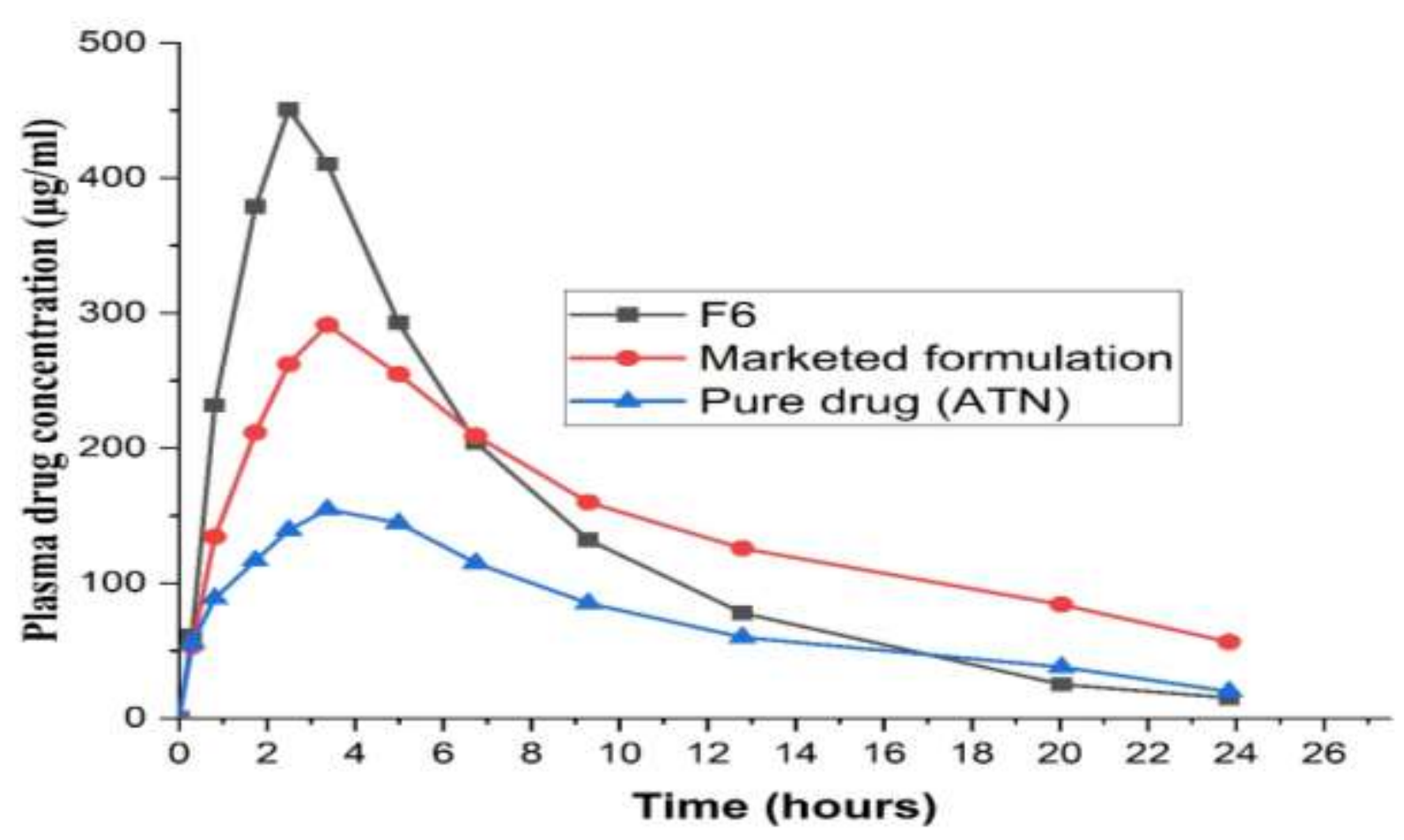

Figure 6: Plasma drug concentration of pure drug (ATN), marketed formulation with best formulation F6.

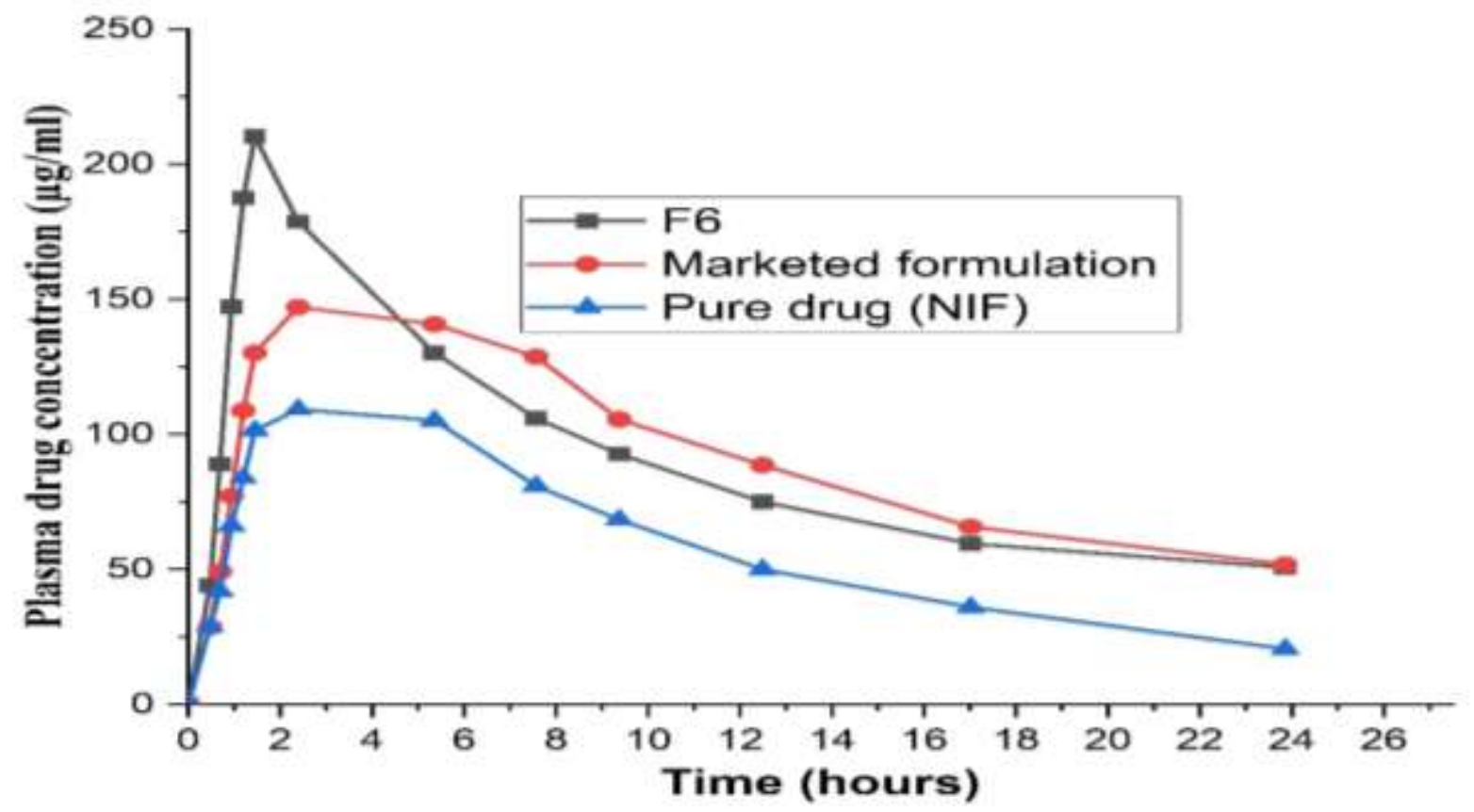

Figure 7: Plasma drug concentration of pure drug (NIF), marketed formulation with best formulation F6.

\section{Antihypertensive activity}

The antihypertensive result for all groups represented in figure 8 . The antihypertensive activity is carried out when blood pressure (systolic) reaches to $180 \mathrm{~mm}$ of $\mathrm{Hg}$ in hypertension induced animal groups (Group II, 
III and IV). The control group (Group I) rats shows normal blood pressure (systolic) $121 \mathrm{mg}$ of $\mathrm{Hg}$. Obtained results confirm that best formulation F6 produces drastic change in lowering the blood pressure (systolic) from 179.93 to 121.76 in $1 \mathrm{~h} 30 \mathrm{~min}$. But marketed formulation shows reduction of blood pressure 181.01 to $121.73 \mathrm{~mm}$ of $\mathrm{Hg}$ in $2 \mathrm{~h} 30 \mathrm{~min}$ for NIF and for Marketed ATN has shown 181.35 to
$121.63 \mathrm{~mm}$ of $\mathrm{Hg}$ at $3 \mathrm{~h}$. But pure drug NIF and ATN have shown 180.72 to $121.66 \mathrm{~mm}$ of $\mathrm{Hg}$ in $3 \mathrm{~h} 30 \mathrm{~min}$ and 180.93 to 121.62 in $5 \mathrm{~h}$ respectively. Formulation F6 has better impact on the hypertensive rat model in this study. From this result, it has been concluded that SLTs considered as a best substitute for commercially available hypertensive tablets and pure form of drugs.

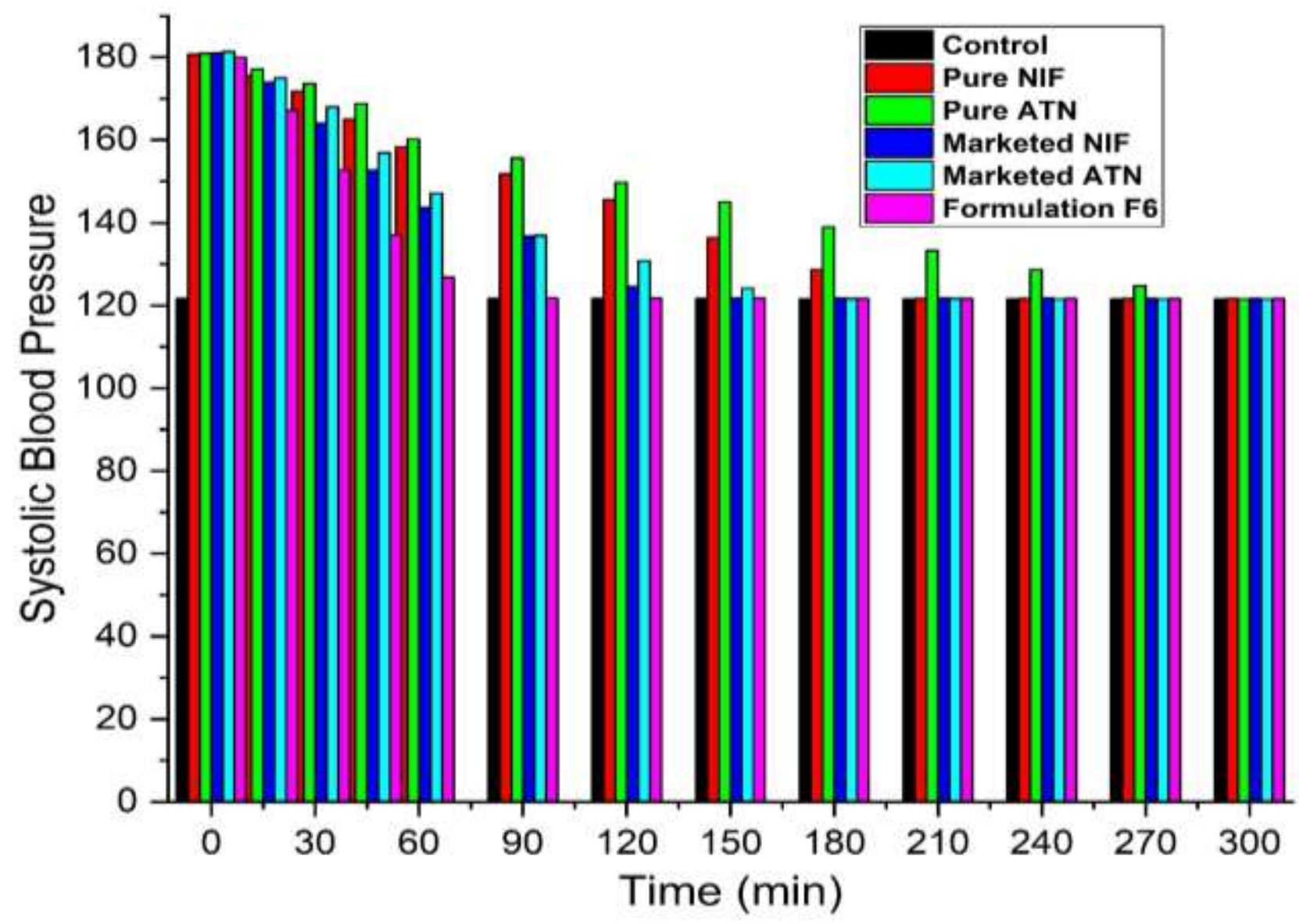

Figure 8: Antihypertensive activity comparison between control, Pure drug (NIF \& ATN), marketed (NIF \& ATN) and best formulation F6.

\section{Stability study}

The selected best formulation F6 is ATN and NIF loaded combined drug delivery for hypertension. Formulation F6 has shown better results in pharmacokinetic studies and antihypertensive activity. Henceforth formulation F6taken for the stability study to determine its self-life shown in Table-6. Self-life is an ultimate goal for the selected formulation.
An accelerated stability study has been performed for 6 months and the result reveals that there are no significant changes found in physical appearance (shape, morphology, and color of the SLTs). A slight deviation was observed in results like drug content $(0.29 \%)$, disintegration time $(1 \mathrm{sec})$, and In vitro dissolution study (1.5\%). The overall result confirms that formulation F6is stable. 
Table 6: Stability study for formulationF6 SLT

\begin{tabular}{|c|c|c|c|c|}
\hline \multirow{2}{*}{ Parameters } & \multicolumn{4}{|c|}{ Optimized formulation F6 } \\
\cline { 2 - 5 } & $\mathbf{0}$ Day & $\mathbf{1}^{\text {st }}$ month & $\mathbf{3}^{\text {rd }}$ month & $\mathbf{6}^{\text {th }}$ month \\
\hline $\begin{array}{c}\text { Physical appearance drug \& } \\
\text { excipients }\end{array}$ & NSC & NSC & NSC & NSC \\
\hline Drug content \% & $99.01 \%$ & $99.32 \%$ & $98.84 \%$ & $98.72 \%$ \\
\hline Disintegration time (sec) & $13.6 \pm .04$ & $13.2 \pm .13$ & $14.1 \pm .71$ & $14.6 \pm .51$ \\
\hline In-vitro drug release \% & $99.71 \%$ & $99.42 \%$ & $98.74 \%$ & $98.21 \%$ \\
\hline
\end{tabular}

All values represent in mean \pm standard deviation, $(n=3)$, NSC: No Significant Changes

\section{Conclusion}

SLTs were formulated in this study in a view of enhancing the treatment facility of hypertension with improved bioavailabilityu.ATN and NIF combinedly loaded SLTs developed aiming to provide a fast disintegration and rapid action of the active dosage form. For a quick disintegration of SLTs a varying concentration of superdisintegrants and sublimating agentsare helpful. It also improves the result of wetting time, in vitro disintegration time and dissolution profile. SLTs quickly disintegrate with saliva without water. FTIR and DSC result confirms the compatibility between drugs and superdisintegrants used in the formulation. Formulation F6 considered as the best formulation based on the results obtained from in vivo pharmacokinetic study and antihypertensive activity. CCS and Camphor composition at higher concentration provide better results for SLTs. Formulation F6 shows
97.36\% drug release at 10 min. with better AUC (Total), $\mathrm{Cmax}$ and $\mathrm{Cl}$ results. . Similarly F6 has shown good antihypertensive results in compare to the marketed formulation and pure drug. Formulation F6 combination of ATN and NIF as SLTs hasshown better performance and selected as a useful candidate for hypertension treatment.

\section{Acknowledgments}

The authors thank the management of Sri Venkateswara College of Pharmacy (Autonomous) for their continuous support and encouragement. The authors also thank and acknowledge DST (F.No.SR/FST/College280/18.11.2015) under FIST Program for providing financial support to the institute.

\section{Conflicts of interest:}

No conflict of interest.

\section{REFERENCES}

1) Franco V, Oparil S, Carretero OA. Hypertensive therapy: part II. Circulation. 2004;109(25):3081-8.

2) Chobanian AV, Bakris GL, Black HR, Cushman WC, Green LA, Izzo Jr JL, Jones DW, Materson BJ, Oparil S, Wright Jr JT, Roccella EJ. The seventh report of the joint national committee on prevention, detection, evaluation, and treatment of high blood pressure: the JNC 7 report. Jama. 2003;289(19):2560-71.

3) Cruickshank JM. New guidelines on hypertension. The Lancet. 2006;368(9536):641.

4) Staessen JA, Fagard R, Thijs L, Celis H, Arabidze GG, Birkenhäger WH, Bulpitt CJ, De Leeuw PW, Dollery CT, Fletcher AE, Forette F. Randomised double-blind comparison of placebo and active treatment for older patients with isolated systolic hypertension. The Lancet. 1997;350(9080):757-64.

5) Swamivelmanickam M, Manavalan R, Valliappan K, Nagar A. Mouth dissolving tablets: an overview. Mouth. 2010;4(5).

6) Sharma G. Mouth dissolving tablets: A current review o. system. 2013;9(10):11.

7) Shinde A, Yadav V, Gaikwad V, Dange S. Fast disintegration drug delivery system: a review. International Journal of Pharmaceutical Sciences and Research. 2013;4(7):2548.

8) Pawar PB, Mansuk AG, Ramteke KH, Sharma YP, Patil SN. Mouth dissolving tablet: A review. International Journal of Herbal Drug Research. 2011;1(2):22-9. 
9) Mudgal VK, Sethi P, Kheri R, Saraogi GK, Singhai AK. Orally disintegrating tablets: a review. International research journal of pharmacy. 2011;2(4):16-22.

10) Basu B, Bagadiya A, Makwana S, Vipul V, Batt D, Dharamsi A. Formulation and evaluation of fast dissolving tablets of cinnarizine using superdisintegrant blends and subliming material. Journal of advanced pharmaceutical technology \& research. 2011;2(4):266.

11) Okhuelegbe ES, Ikhuoria AM, Ike AA. Evaluation of fast disintegrating tablets of Nifedipine prepared by Superdisintegrant addition and sublimation methods. Dhaka University Journal of Pharmaceutical Sciences. 2014;13(2):199-205.

12) Okhuelegbe ES, Ikhuoria AM, Ike AA. Evaluation of fast disintegrating tablets of Nifedipine prepared by Superdisintegrant addition and sublimation methods. Dhaka Uni. J. Pharm. Sci. 2014; 13 (2):199-205.

13) Monajjemzadeh F, Hassanzadeh D, Valizadeh H, Siahi-Shadbad MR, Mojarrad JS, Robertson TA, Roberts MS. Compatibility studies of acyclovir and lactose in physical mixtures and commercial tablets. European journal of pharmaceutics and biopharmaceutics. 2009;73(3):404-13.

14) Canbay HS, Polat M, Doğantürk M. Study of Stability and Drug-Excipient Compatibility of Estriol. Bilge International Journal of Science and Technology Research. 2019;3(2):102-7.

15) Thulluru A, Madhavi C, Nandini K, Sirisha S, Spandana D. Role of Co-Processed Superdisintegrants in Enhancing the Dissolution Rate of Nifedipine in Sublingual Tablets. Asian J. Pharm. Res. 2019; 9 (4):253-259.

16) Bhosale NR, Kolte NS. Formulation development and evaluation of orally disintegrating tablet of chlorpheneramine maleate by sublimation technique. Int. J. Pharm. Pharm. Sci. 2019; 11 (9):28-36.

17) Monajjemzadeh F, Hassanzadeh D, Valizadeh H, Siahi-Shadbad MR, Mojarrad JS, Robertson TA, Roberts MS. Compatibility studies of acyclovir and lactose in physical mixtures and commercial tablets. European journal of pharmaceutics and biopharmaceutics. 2009;73(3):404-13.

18) Mishra B, Mohanty B, Barik CS. Formulation Development and Evaluation of Direct compressed Cefpodoxime proxetil Effervescent Tablets. Research Journal of Pharmacy and Technology. 2019;12(6):2695-9.

19) Haque SE, Sheela A. Development of polymer-bound fast-dissolving metformin buccal film with disintegrants. International journal of nanomedicine. 2015;10(Suppl 1):199.

20) Kacso I, Rus LM, Martin F, Miclaus M, Filip X, Dan M. Solid-state compatibility studies of Ketoconazole-Fumaric acid co-crystal with tablet excipients. Journal of Thermal Analysis and Calorimetry. 2021;143(5):3499-506.

21) Haque SE, Sheela A. Design and in vitro evaluation of interpolymer complex bound metformin sustained release tablet. Journal of Applied Polymer Science. 2014;131(21).

22) Haque SE, Sheela A. Biocompatible interpolymer complex matrix tablets-an oral sustained release class-III antidiabetic drug. InIOP Conference Series: Materials Science and Engineering 2017 (Vol. 263, No. 2, p. 022030). IOP Publishing.

23) Khemariya P, Gajbhiye KR, Vaidya VD, Jadon RS, Mishra S, Shukla A, Bhargava M, Singhai SK, Goswami S. Preparation and evaluation of mouth dissolving tablets of meloxicam. International Journal of Drug Delivery. 2010;2(1).

24) Devarakonda B, Hill RA, de Villiers MM. The effect of PAMAM dendrimer generation size and surface functional group on the aqueous solubility of nifedipine. Int. J. Pharm. 2004; 284 (1-2):133140.

25) Bi Y, Sunada H, Yonezawa Y, Danjo K, Otsuka A, IIDA K. Preparation and evaluation of a compressed tablet rapidly disintegrating in the oral cavity. Chem pharm bulletin. 1996; 44(11):21212127

26) Huang M, Chen J, Hu X, Liu J, Wu G, Zhou H, Zhu MX, Wu L, ShenTu J. Comparative bioavailability and pharmacokinetics of sirolimus tablets in healthy Chinese volunteers. Intenational Journal of Clinical Pharmacology Therapy and Toxicology. 2013;51 (10): 816-822. 
27) Raoof AA, Chiu P, Ramtoola Z, Cumming IK., Teng C, Weinbach SP, Hardee GE, Levin AA, Geary RS. Oral bioavailability and multiple dose tolerability of an antisense oligonucleotide tablet formulated with sodium caprate. Journal of Pharmaceutical Sciences. 2004;93 (6):1431-1439.

28) Saravanakumar M, Raja B. Veratric acid, a phenolic acid attenuates blood pressure and oxidative stress in L-NAME induced hypertensive rats. European Journal of Pharmacology. 2011; 671 (1-3): 87-94.

29) Sung JH, Jo YS, Kim SJ, Ryu JS, Kim MC, Ko HJ, Sim SS. Effect of lutein on L-NAME-induced hypertensive rats. Korean Journal of Physiology and Pharmacology. 2013; 17 (4) :339-345. 